\title{
A breast-feeding promotion and support program a randomized trial in The Netherlands
}

Citation for published version (APA):

Kools-Anten, E. J., Thijs, C. T., Kester, A. D. M., van den Brandt, P. A., \& de Vries, H. (2005). A breastfeeding promotion and support program a randomized trial in The Netherlands. Preventive Medicine, 40(1), 60-70. https://doi.org/10.1016/j.ypmed.2004.05.013

Document status and date:

Published: 01/01/2005

DOI:

10.1016/j.ypmed.2004.05.013

Document Version:

Publisher's PDF, also known as Version of record

\section{Please check the document version of this publication:}

- A submitted manuscript is the version of the article upon submission and before peer-review. There can be important differences between the submitted version and the official published version of record.

People interested in the research are advised to contact the author for the final version of the publication, or visit the DOI to the publisher's website.

- The final author version and the galley proof are versions of the publication after peer review.

- The final published version features the final layout of the paper including the volume, issue and page numbers.

Link to publication

\footnotetext{
General rights rights.

- You may freely distribute the URL identifying the publication in the public portal. please follow below link for the End User Agreement:

www.umlib.nl/taverne-license

Take down policy

If you believe that this document breaches copyright please contact us at:

repository@maastrichtuniversity.nl

providing details and we will investigate your claim.
}

Copyright and moral rights for the publications made accessible in the public portal are retained by the authors and/or other copyright owners and it is a condition of accessing publications that users recognise and abide by the legal requirements associated with these

- Users may download and print one copy of any publication from the public portal for the purpose of private study or research.

- You may not further distribute the material or use it for any profit-making activity or commercial gain

If the publication is distributed under the terms of Article $25 \mathrm{fa}$ of the Dutch Copyright Act, indicated by the "Taverne" license above, 


\title{
A breast-feeding promotion and support program a randomized trial in the Netherlands
}

\author{
Els J. Kools, M.D., M.P.H., ${ }^{\text {a** }}$ Carel Thijs, M.D., M.P.H., Ph.D., ${ }^{a}$ \\ Arnold D.M. Kester, Ph.D., ${ }^{b}$ Piet A. van den Brandt, Ph.D., ${ }^{a}$ and Hein de Vries, Ph.D. ${ }^{c}$ \\ ${ }^{a}$ Department of Epidemiology, Maastricht University, 6200 MD Maastricht, The Netherlands \\ ${ }^{\mathrm{b}}$ Department of Methodology and Statistics, Maastricht University, Maastricht, The Netherlands \\ ${ }^{\mathrm{c}}$ Department of Health Education and Promotion, Maastricht University, Maastricht, The Netherlands
}

Available online 14 July 2004

\begin{abstract}
Background. In the Netherlands, the initiation rate of breast-feeding (BF) was $80 \%$ in 2002, but only $35 \%$ of the mothers continued to breast-feed for 3 months. This study examined the effectiveness of a breast-feeding promotion program to increase the continuation of breast-feeding.

Methods. A cluster-randomized intervention trial was used. Ten child health care centers in three regions of the home health care were randomly allocated to the program or usual care. Elements in the program were health counseling, measures to enhance cooperation, early signaling of breast-feeding problems and continuity of care, and lactation consultancy. Pregnant mothers who applied for home health care in the intervention or usual care regions were enrolled and were followed up from pregnancy until 6 months postpartum $(n=683)$. The primary outcome measure was the continuation of breast-feeding until at least 3 months.

Results. The 3-month breast-feeding rate was $32 \%$ in the intervention and $38 \%$ in the control groups $(\mathrm{OR}=0.79,95 \% \mathrm{CI}=0.58-1.08)$.

Conclusion. The program was not effective. We discuss possible explanations from the design and execution of the trial and give some points for improvement of our program, such as the categories of caregivers involved and the number and duration of contacts after parturition.
\end{abstract}

(C) 2004 The Institute For Cancer Prevention and Elsevier Inc. All rights reserved.

Keywords: Breast-feeding; Weaning; I-change model; Attitude; Social influences; Self-efficacy

\section{Introduction}

In the Netherlands, $80 \%$ of mothers start with breastfeeding $(\mathrm{BF})$, but the rate drops rapidly during the first month postpartum to $52 \%$, to decrease further to $35 \%$ at 3 months and $17 \%$ at 6 months [1]. To improve BF practices, initiatives have concentrated on procedures and policies in health care. Considering the low rate of long-term BF, more emphasis is needed to promote and support the continuation of $\mathrm{BF}$ in addition promoting its initiation. At present, Dutch programs are mainly based on increasing knowledge and not on actual support of BF. Counseling of BF is an important part of the responsibilities of the Dutch caregivers in depart-

* Corresponding author. Department of Epidemiology, Maastricht University, PO Box 616, 6200 MD Maastricht, The Netherlands. Fax: +31-43-388-4128.

E-mail address: els.anten@epid.unimaas.nl (E.J. Kools). ments of maternity and child health care. Early detection of barriers and problems of $\mathrm{BF}$ and monitoring of mothers at risk for early weaning are currently not embedded structurally in programs of maternity and child health care. The great popularity and the easy accessibility of the public services for maternity and child health care by the Dutch home health care organizations and their professionalism provide relevant gateways to access mothers to promote $\mathrm{BF}$ and preventing discontinuation.

Several programs on breast-feeding promotion and support have been developed, and reviews of randomized trials have shown that some programs were effective, while others were not $[2,3]$. Effective interventions generally composed a mix of elements. The goal of the study is to develop and test a program for Dutch women. Program planning was guided by the application of a planning model [4] and on analysis of behavioral determinants of breast-feeding duration [5], using the I-change model [6-8]. 
The main goal of the program was to prevent mothers to refrain from discontinuation and to enhance the $\mathrm{BF}$ rate at 3 months by $10 \%$, from $21 \%$ (in 1999 in the participating centers) to $31 \%$. The rationale for the choice for 3 months is that the greatest health benefits can be reached for the baby during the first 6 months. We formulated our operational goals as follows [4]: to strengthen the support of continuation of $\mathrm{BF}$ (in addition to promotion of the initiation of BF) by (1) health counseling: intervening on behavioral determinants of the duration of BF by enhancing the caregiver's performance to promote and support BF using health counseling principles; (2) cooperation and continuity: to enhance cooperation, early signaling of $\mathrm{BF}$ problems, and continuity of care by transfer of information on individual mothers between caregivers; and (3) lactation consultancy: to take away financial and practical barriers for consulting lactation consultants [9].

Exclusive BF (EBF) was defined according the WHO definitions [10] as breast-feeding without supplemental liquids or solid foods other than medicines or vitamins; and complementary breast-feeding (CBF) was defined as breast milk complemented by formula food or solid food. Formula feeding (FF) meant feeding an infant with formula feeds with no breast-feeding at all. In this study, breastfeeding (BF) meant all feeding practices in combination with breast milk (EBF plus $\mathrm{CBF}$ ).

\section{Methods}

\section{Study design and sample size}

We used a cluster-randomized design for the trial. The sample size was calculated for an expected absolute increase of at least $10 \% \mathrm{BF}$ at 3 months (from $21 \%$ in the control regions, that is, the preintervention rate in the three participating Home Care Organizations, to $31 \%$ in the intervention regions). Power calculations with an alpha of 0.05 (for an one-tailed test) and a power of $80 \%$ revealed that 253 participants were needed in each group with complete follow-up.

The study received approval from the medical ethical committee of the Academic Hospital Maastricht/Maastricht University.

\section{Selection and randomization of centers}

Three out of five home health care organizations in the province of Limburg, the most southern province of the Netherlands, participated. In these organizations, 10 geographically separated centers of maternity and child health care were selected. They were grouped into two clusters, A and B, based on similarity of BF rates in 1999 from the annual reports of the home health care centers (prerandomization rate) and on the number of children born in 1999 receiving care in the centers (prerandomization size), so that clusters A and B had comparable overall prerandomization rates and sizes. On a meeting of the steering committee, who were unaware of the characteristics of the centers, a coin flip determined that the $\mathrm{B}$ centers would receive the experimental intervention and the A centers would receive the control intervention. The prerandomization BF rate was $19.0 \%$ in the intervention centers and $21.6 \%$ in the control centers.

\section{Recruitment, informed consent, and follow-up}

Study candidates were pregnant women who applied for maternity care in the intervention or control centers of the three home health care organizations from December 2000December 2002. About $60 \%$ of pregnant mothers were users of this maternity care; the remaining mothers used similar care from commercial organizations (not included in this study).

Typically, pregnant Dutch women apply between the 6th and 7th months of pregnancy for maternity care; then they receive a home visit by a maternity care nurse in the 7th or 8th month. The candidates from the intake list of the maternity care were sent an informed consent letter with the first questionnaire (T0) to be returned during the prepartum home visit. Those who agreed to participate received three follow-up questionnaires; the first (T1) 14 days postpartum during the postpartum home visit of the child health care nurse, and the second (T2) and third (T3) questionnaires at 2 and 5 months postpartum during the consultations at the child health center. The questionnaires had to be returned during the consultations at 1,3 , and 6 months postpartum. If participants failed to return a questionnaire, they were telephoned to obtain the most essential follow-up information including BF continuation.

The information in the informed consent letter did not reveal which center was in the control group as it was identical for the intervention and control groups. Care was taken that no other information was made public on whether a center belonged to the intervention or to the control groups to avoid selection by pregnant women towards the intervention of their choice.

Participants with infants with a birth weight less than $2,000 \mathrm{~g}$ were excluded from the analysis.

\section{The intervention program}

To assess the behavioral determinants in our local situation, a preceding study based on the integrated model for motivational and behavioral change (I-change model) [6-8] was started in 1999. The program was targeted at pregnant women in their 7th month of the pregnancy. The operational goals were addressed by the following elements:

1. Health counseling: To facilitate the counseling process for caregivers, the health counseling ( $\mathrm{HC}$ ) model was chosen $[11,12]$ since this model had already been applied successfully to other health promoting behaviors, such as smoking prevention $[13,14]$. Both process and effect 
evaluations revealed its feasibility, appeal, and effectiveness [14]. The HC model was based on theories of behavioral change. The HC process consists of three phases: preparation of the advice, implementation of the advice, and maintenance. These phases were worked out in six steps addressing the behavioral determinants from our previous study [5]. We used a program matrix [15] adapted for health promotion [16,17] (Table 1).

2. Cooperation and continuity: A mother's booklet was developed to enhance cooperation between caregivers of the maternity and child health care to give early signaling of $\mathrm{BF}$ problems and to transfer information between caregivers. In this booklet, we described the six HC steps and mentioned the BF barriers mothers could encounter during each regular contact with caregivers. The mother's booklet was handed out, if the woman had decided to breast-feed or was still contemplating it during this visit, and the women were asked to log their BF barriers, problems, and motivation to continue $\mathrm{BF}$ before each next regular contact with the caregivers. The mother could also find a telephone number to reach the caregiver in case BF questions or problems arose. The caregivers in the intervention centers used the mother's booklet during each consultation and used health counseling principles with the help of the program.

3. Lactation consultancy: To enhance access to lactation consultants and to reduce financial and practical barriers for consulting them, three lactation consultants in our region were appointed and paid by Maastricht University and their services were free of charge. The lactation consultants in the intervention regions were $24 \mathrm{~h}$ obtainable by fax. An agreement was reached on the indications and procedures for referrals to the lactation consultants. The caregivers could fax their concerns or queries about $\mathrm{BF}$ on a structured form to the lactation consultant. After receiving the fax, the lactation consultants contacted the caregiver or the mother within $24 \mathrm{~h}$ and tried to resolve the problems. If needed they could made home visits or follow-up calls.

For the caregivers, a counseling protocol was developed with a one-page summary for each group: for the maternity and child health care nurse and for the physician. The aim of the summary was a prompt for the steps and a resource for answering questions. The summary consisted of answers to the most frequent questions and barriers regarding early weaning that women encountered with BF.

The following caregivers were involved with the program: the maternity nurse (prepartum home visits), the nurse (postpartum home visits and consultations), and physicians (consultations) of the child health care and lactation consultants. The participation of midwives in our study could not be guaranteed since their workload had increased in recent years.

At the end of 2000, the caregivers (the maternity nurses and the child health care nurses and physicians) were trained in a 4-h session in using the program and in counseling skills by demonstration and role-play. They received a written instruction how to use the devices for early signaling of $\mathrm{BF}$ problems and how to solve them and received instructions for cooperation between caregivers. These instructions were discussed during the training. The training was followed by a lesson of $2 \mathrm{~h}$ on the role of lactation consultants and the indications for referring mothers to them. Practical problems were discussed during two refresh training sessions of $2 \mathrm{~h}$.

After the training, the program was started during the prepartum home visit by the maternity nurse in the intervention centers. The program started in the beginning of 2001 and executed until the last mother had completed the 3-month follow-up. Free access to lactation consultants was

Table 1

An application of the program matrix to breast-feeding

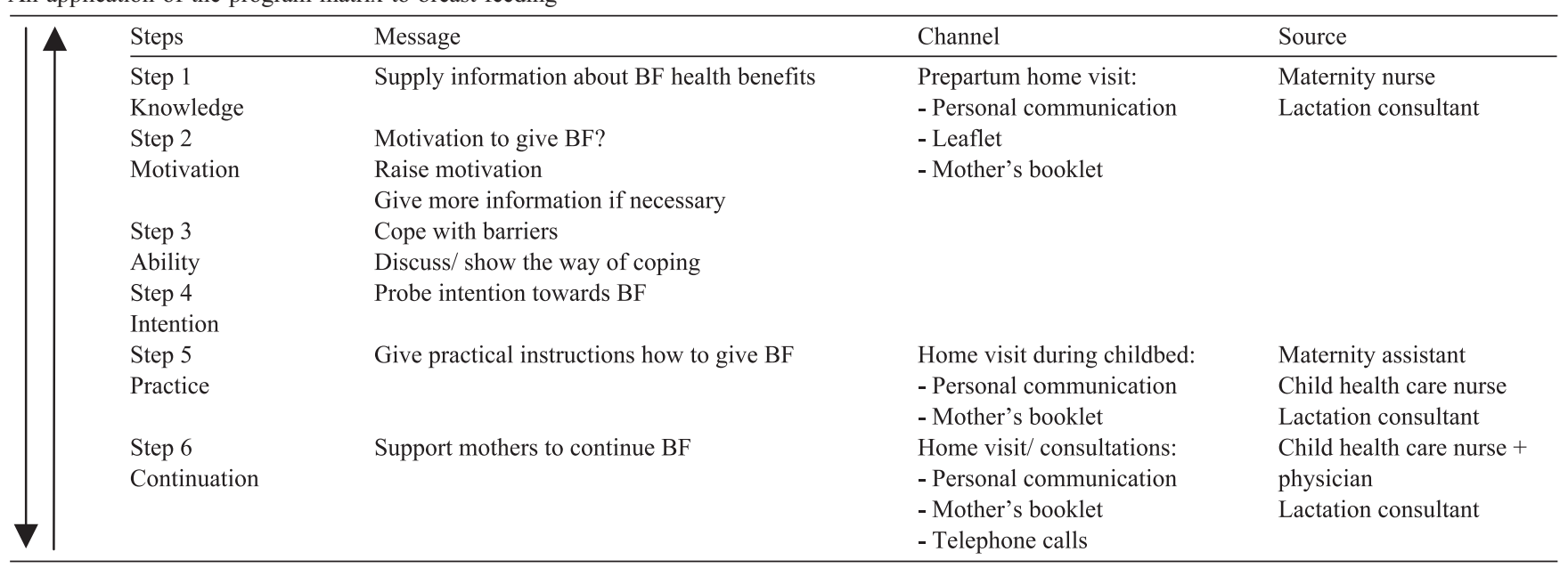

$\mathrm{BF}=$ breast-feeding. 
restricted to the participating mothers in the intervention group. Health counseling principles and mothers' booklets were applied for all mothers in the intervention centers, including the nonparticipants.

\section{Baseline measurements}

In the prepartum questionnaire (T0), taken from the mothers before the first intervention, the following baseline characteristics were measured: maternal age, maternal education, previous $\mathrm{BF}$ experience, and the intention to give $\mathrm{BF}$ or formula feeding; and the ASE determinants: attitude (A), social norm (S), and self-efficacy (E). The ASE items were based on results of our previous study [5] and are fully described elsewhere [18]. Attitudes toward BF were assessed by asking the perceived advantages (pros) of BF in relation to the mother herself, to her infant, and to her partner. Beliefs regarding social norms and support were measured from significant others (such as partner, mother, sister, friends, midwife, maternity and child health care nurse and physician, colleague, and employer). A distinction was made between self-efficacy to breast-feed and to formula feed, assessing both situational and stress selfefficacy for both types of feeding.

In the first postpartum questionnaire (T1), information pertinent to the exclusion criterion was sought: the birth weight of the infant. In this questionnaire, we also asked which feeding had been started after delivery.

To assess baseline comparability of the knowledge of the caregivers about BF, we used a multiple-choice test developed by the Dutch Association for Lactation Consultants. About 3 months before the start of the intervention, this test was taken by all the caregivers of the maternity and child health care in the intervention and control regions.

\section{Outcome measurements}

As the main outcome measurement, the 3-month postpartum questionnaire (T2) asked whether the mother used exclusive BF, complementary BF, or formula at that moment and the number of weeks of exclusive or complementary BF continuation.

In the year 2000 (1 year before the start of the intervention), the caregivers in both intervention and control regions recorded registry forms during the consultations for all infants born in these regions until the last mother was included in May 2003. They recorded birth weight, feeding practices, and the timing of discontinuing of BF at birth, 1 , 3 , and 6 months. This registry form was pretested in one home health care organization during 1999.

\section{Process and program evaluation}

To get insight in the process of counseling, the questionnaire at 6 months postpartum (T3) in both the intervention and control groups asked whether they were satisfied with the feeding advice of the caregivers, whether the caregivers took their opinion into account, and whether they had received any contradictory feeding advice. For the evaluation of the program, we asked mothers in the intervention group who still gave $\mathrm{BF}$ at 6 months postpartum (T3 questionnaire) on the usage and usefulness of the mother's booklet.

To gain insight into the process of the intervention at the caregiver level, the caregivers of the intervention and control regions filled in a questionnaire 3 months after the last mother had been included. This asked about how desirable they found to consult or to refer to a lactation consultant and their satisfaction with the care. For the program evaluation, extra questions for the caregivers in the intervention groups were added about their attitude, their support from others, and their self-efficacy to carry out the program. Furthermore, we asked whether the program took more time than usual, as well as how much time they had spent on BF counseling per consultation, the report mark of the program, their willingness to carry out the program in the future, and their opinion about the implementation on a national scale. The lactation consultants themselves recorded the BF problems they encountered and the advice they had given on a structured form at each contact with the mothers.

\section{Analyses}

Chi-square tests for categorical variables and $t$ tests for continuous variables were used to compare breast- and formula-feeding mothers. For each ASE concept, a mean score was computed by averaging the scores on the items. Reliability analyses assessed the reliability (expressed as Cronbach's alpha) of the perceived pros and cons, social influences, and self-efficacy scores. The main effect of the intervention on the primary outcome [the proportion of mothers who breast-feed $(\mathrm{EBF}+\mathrm{CBF})$ at 3 months] was analyzed at two levels: at the level of the participating mothers (questionnaires) and at the level of the caregivers (registry forms) by comparing the proportion between the intervention and control groups, using the chi-square test. Univariate logistic regression was used to compute odds ratios with 95\% confidence intervals. At the individual level, multivariate logistic regression was used to account for potential baseline differences of maternal age, maternal education, and previous BF experience. Modification of the intervention effect by these determinants was evaluated by testing for interaction, with a cutoff point of 0.10 for the $P$ value of the interaction term.

In a multilevel analysis, a random intercepts logistic regression model was used to account for variability of $\mathrm{BF}$ rates between the 10 centers (including regional differences), using postcodes of the participants to group them into the regions belonging to the various centers.

Cox's regression analysis was used to test the differences between the survival rates with correction for covariates, 
where survival was defined as continuation of BF. Survival curves corrected for covariates were derived from a stratified Cox's regression model (stratified by group).

The analyses were carried out in STATA 7.0 [19].

\section{Results}

During the study period December 2000-December 2002, 10 centers were randomized into five intervention and five control centers. Five hundred and seventy pregnant women were applied for maternity care at the five intervention centers and $518 \mathrm{did}$ so at the five control centers (Fig. 1). Of these candidates, 408 (72\%) and 373 (72\%) agreed to participate. At the mothers' first consul- tation at the center at 1 month after birth, 364 mothers in the intervention group and 318 in the control group returned the first follow-up questionnaire (T1). From most nonresponders, backup data on birth weight and BF were obtained from the registry forms, so that information was complete on 408 mothers in the intervention group and 368 in the control group. Thirty-seven and 38 mothers from the respective groups were excluded so that 371 $(91 \%)$ mothers remained in the intervention group and 330 $(88 \%)$ in the control group (Total T1). Reasons to exclude respondents were as follows: mothers did not return the baseline questionnaire or filled in this questionnaire after the prepartum home visit when the intervention had already started $(n=15)$; mothers had cancelled the maternity care of the home health care before the home

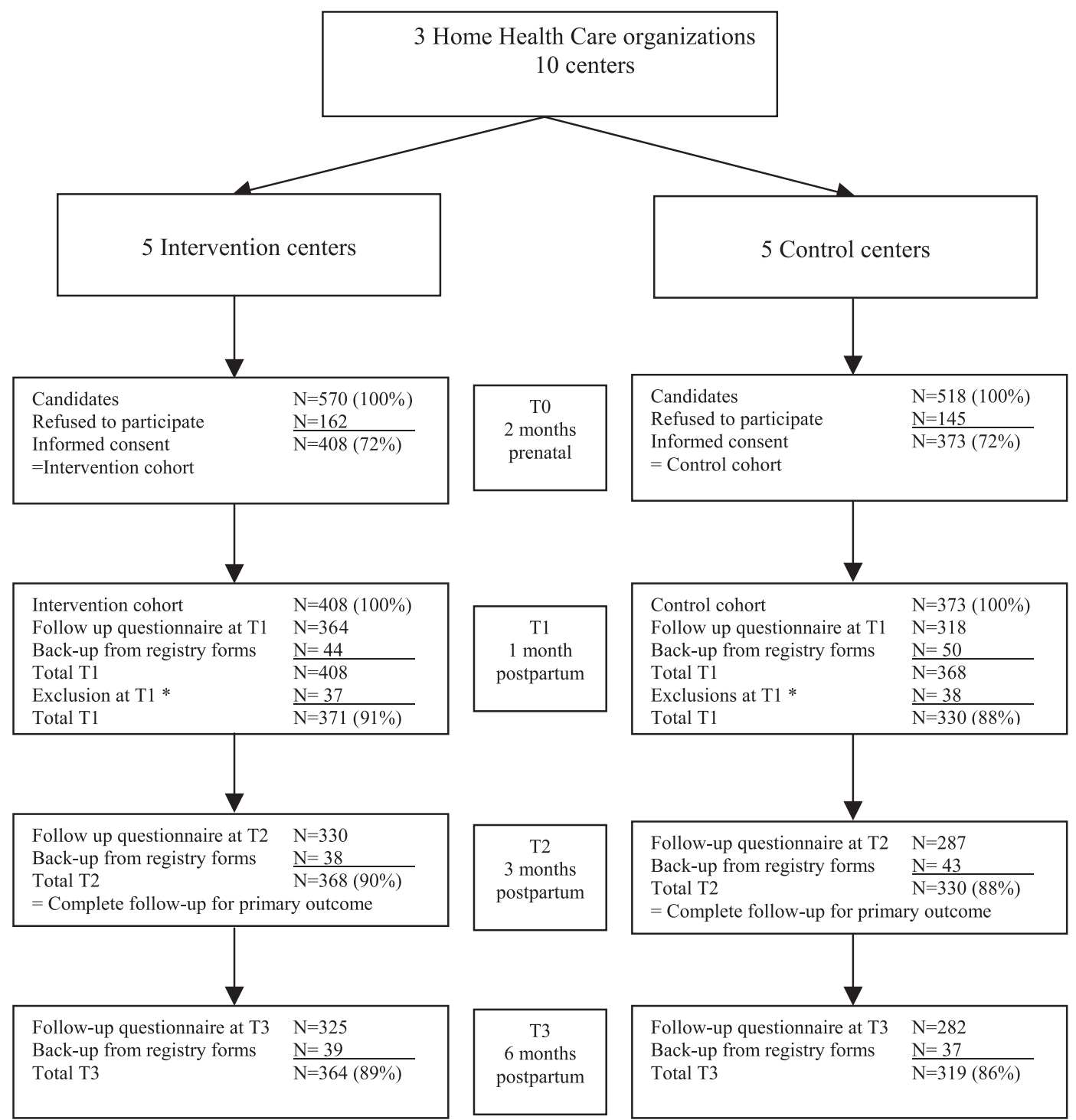

* Exclusion: no T0 or filled in T0 to late for baseline (after prenatal home visit); no maternity care or no data available; birth weight $<2,000 \mathrm{~g}$ or no birth weight data available

Fig. 1. The trial profile. 
visit $(n=31)$; the kind of maternity care was not filled in by the participant $(n=23)$; and birth weight of the infants was less than $2,000 \mathrm{~g}(n=15)$ or was unknown $(n=21$, the totals exceeded the totals of 37 and 38, respectively, because combinations of reasons were possible). At 3 months postpartum, the additional nonresponse to the questionnaires could almost be fully backed up with registry data so that the number of participants with complete follow-up for the primary outcome (Total T2) was $368(90 \%)$ in the intervention group and $330(88 \%)$ in the control group. At 6 months postpartum, the additional nonresponse was similarly backed up with the help of the registry data (Fig. 1).

The caregivers filled in 2,734 registry forms, namely, 947 forms in 2000, 1,378 in 2001, and 409 forms in 2002. These numbers are higher than the number of participating mothers because registry forms were filled in for all infants born in the intervention and control centers (including those of mothers not on the intake list for maternity care, and those of mothers who refused to participate or who were excluded). It was possible to link 406 registry forms to the mothers' questionnaire data in an anonymous way, showing only 17 (4\%) discrepancies on the duration of BF.

\section{Baseline characteristics of the participants and caregivers}

No dropout analyses were performed since only three participants were lost to follow-up in the intervention group and none in the control group (Fig. 1). Table 2 shows the baseline personal and ASE characteristics of the participants from the prepartum questionnaire (T0). The mean age of the pregnant mothers was 31 years ranging from 19 to 43 years; most of the mothers had a middle level of education and were primiparas. The intervention and control groups did not differed only slightly at baseline for age, maternal education, previous BF experience, and for ASE determinants. In the intervention group, fewer mothers had the intention to breast-feed $(66 \%)$ than in the control group (71\%).

The scores of the baseline knowledge test in caregivers were unsatisfactory $(<5.5$ on a $1-10$ scale) in $19 \%(6 / 31)$ at the intervention centers and $29 \%(6 / 21)$ at the control

Table 2

Comparison of the baseline characteristics of the complete follow-up of the intervention and control group at 3 months $(n=698)$

\begin{tabular}{|c|c|c|c|c|c|c|}
\hline \multirow[t]{2}{*}{ Characteristics } & & \multirow[t]{2}{*}{ Scale } & \multirow{2}{*}{$\begin{array}{l}\text { Cronbach's } \\
\text { alpha }\end{array}$} & \multicolumn{3}{|c|}{ Complete follow-up at 3 months } \\
\hline & & & & Intervention cohort & Control cohort & $P$ value ${ }^{\mathrm{a}}$ \\
\hline All mothers & & & & $N=368(100 \%)$ & $N=330(100 \%)$ & \\
\hline Intention to breast-feed & & & & $243(66 \%)$ & $233(71 \%)$ & 0.20 \\
\hline \multirow[t]{3}{*}{ Maternal age } & $<25$ years old & & & $37(10 \%)$ & $26(8 \%)$ & \\
\hline & $25-30$ years old & & & $163(44 \%)$ & $148(45 \%)$ & \\
\hline & $\geq 31$ years old & & & $168(46 \%)$ & $156(47 \%)$ & 0.60 \\
\hline \multirow[t]{3}{*}{ Maternal education $^{\mathrm{b}}$} & Low & & & $77(21 \%)$ & $61(18 \%)$ & \\
\hline & Middle & & & $196(53 \%)$ & $194(59 \%)$ & \\
\hline & High & & & $95(26 \%)$ & $75(23 \%)$ & 0.34 \\
\hline \multirow[t]{3}{*}{ Previous BF } & No, multiparas & & & $63(17 \%)$ & $45(14 \%)$ & \\
\hline & Yes, multiparas & & & $98(27 \%)$ & $102(31 \%)$ & \\
\hline & No, primiparas & & & $207(56 \%)$ & $183(55 \%)$ & 0.29 \\
\hline \multicolumn{4}{|l|}{ ASE determinants } & Mean $(\mathrm{SD})^{\mathrm{c}}$ & Mean $(\mathrm{SD})^{\mathrm{c}}$ & $P$ value ${ }^{\mathrm{c}}$ \\
\hline \multirow[t]{2}{*}{ Attitude } & Pros BF & $1-5^{\mathrm{d}}$ & 0.80 & $3.27(0.60)$ & $3.24(0.62)$ & 0.42 \\
\hline & Cons BF & $1-5^{\mathrm{d}}$ & 0.73 & $2.84(0.45)$ & $2.80(0.43)$ & 0.21 \\
\hline \multirow[t]{2}{*}{ Social norm } & Significant others & $1-5^{\mathrm{e}}$ & 0.78 & $3.45(0.59)$ & $3.48(0.59)$ & 0.43 \\
\hline & Work & $1-5^{\mathrm{e}}$ & 0.54 & $3.07(0.35)$ & $3.10(0.44)$ & 0.41 \\
\hline \multirow[t]{2}{*}{ Social support BF } & Significant others & $1-5^{f}$ & 0.83 & $2.52(1.16)$ & $2.60(1.10)$ & 0.33 \\
\hline & Work & $1-5^{f}$ & 0.79 & $1.39(0.82)$ & $1.48(0.93)$ & 0.15 \\
\hline \multirow[t]{2}{*}{ Social support FF } & Significant others & $1-5^{\mathrm{f}}$ & 0.88 & $2.13(0.98)$ & $2.15(1.08)$ & 0.85 \\
\hline & Work & $1-5^{\mathrm{f}}$ & 0.82 & $1.18(0.88)$ & $1.41(0.89)$ & 0.61 \\
\hline \multirow[t]{2}{*}{ Self-efficacy BF } & Situational & $1-7^{\mathrm{g}}$ & 0.81 & $4.04(1.15)$ & 4.08 (1.09) & 0.62 \\
\hline & Stress & $1-7^{g}$ & 0.83 & $3.19(1.08)$ & $3.17(1.10)$ & 0.78 \\
\hline \multirow[t]{2}{*}{ Self-efficacy FF } & Situational & $1-7^{g}$ & 0.76 & $5.37(0.90)$ & $5.37(0.92)$ & 0.93 \\
\hline & Stress & $1-7^{g}$ & 0.84 & $5.11(1.06)$ & $5.05(1.07)$ & 0.45 \\
\hline
\end{tabular}

$\mathrm{BF}=$ breast-feeding; $\mathrm{FF}=$ formula feeding.

${ }^{a}$ From Pearson chi-square test.

${ }^{\mathrm{b}}$ Low: primary or basic vocational school; middle: secondary vocational or high school; high: higher vocational school or university.

${ }^{\mathrm{c}}$ From $t$ test.

${ }^{\mathrm{d}} 1$ = fully agree, 5 = fully disagree with the advantages (pros) or disadvantages (cons) of breastfeeding.

e 1 = I must certainly breast-feed, 5 = I must certainly formula feed.

${ }^{\mathrm{f}} 1$ = very often support, $5=$ never support for breastfeeding or formula feeding.

g $1=$ very difficult, 7 = very easy to give breastfeeding or formula feeding. 
centers, but the mean scores were comparable [6.0 (SD $1.00)$ and 5.8 (SD 1.32), respectively].

\section{Breast-feeding outcomes}

The percentage of mothers who started breast-feeding was 68 in the intervention cohort and 72 in the control group, which was not very different from the prepartum intention in either group (66 and 71; Table 3). At 3 months, $32 \%$ continued $\mathrm{BF}$ in the intervention group and $38 \%$ in the control group. The multivariate logistic regression analysis (random intercepts model) did not reveal significant effect of the intervention either $(\mathrm{OR}=$ $0.82,95 \% \mathrm{CI}=0.58-1.14)$, Table 4. Predictors of $\mathrm{BF}$ continuation until at least 3 months were as follows: maternal education (high level $\mathrm{OR}=4.36$; middle level $\mathrm{OR}=1.98)$ compared with low level; and multiparity with previous $\mathrm{BF}$ experience $(\mathrm{OR}=10.56)$ and primiparity $(\mathrm{OR}=5.74)$ compared with multiparity without previous $\mathrm{BF}$ experience.

To evaluate whether the effect of the intervention depended on maternal age, maternal education, or previous $\mathrm{BF}$ experience, these variables were entered as interaction terms with the intervention in the multivariate logistic regression model. None of the interactions between the main outcome and the covariables reached statistical significance at the level of $P<0.10$. Because the prepartum intention to give BF was a very strong determinant of $\mathrm{BF}$ initiation, it was not possible to adjust for intention in the same model. Consequently, a stratified analysis of Table 3 by intention was run. Of the women who intended to breast-feed, 98\% (238/244) in the intervention group and $98 \%(228 / 233)$ in the control group initiated $\mathrm{BF}$ at birth $(\mathrm{OR}=0.86,95 \%$ CI $0.26-2.89) 48 \%(116 / 243)$ and $53 \%(122 / 233)$ continued at least 3 months $(\mathrm{OR}=0.83$,

Table 3

Questionnaires from the mothers: breast-feeding at birth and at 3 months

\begin{tabular}{|c|c|c|c|c|c|c|}
\hline & \multicolumn{2}{|c|}{ Intervention group } & \multicolumn{2}{|c|}{ Control group } & \multirow[t]{2}{*}{$\mathrm{OR}^{\mathrm{a}}$} & \multirow[t]{2}{*}{$95 \% \mathrm{CI}$} \\
\hline & No. & $\%$ & No. & $\%$ & & \\
\hline Feeding at birth & 371 & 100 & 330 & 100 & & \\
\hline $\begin{array}{l}\text { Exclusive } \\
\text { breast-feeding }\end{array}$ & 225 & 61 & 222 & 67 & 0.80 & $0.57-1.11$ \\
\hline $\begin{array}{c}\text { Complementary } \\
\text { breast-feeding }\end{array}$ & 29 & 8 & 16 & 5 & 1.43 & $0.73-2.78$ \\
\hline $\begin{array}{l}\text { Total } \\
\text { breast-feeding }\end{array}$ & 254 & 68 & 238 & 72 & 0.84 & $0.61-1.16$ \\
\hline $\begin{array}{l}\text { Feeding at } \\
3 \text { months }\end{array}$ & 368 & 100 & 330 & 100 & & \\
\hline $\begin{array}{l}\text { Exclusive } \\
\text { breast-feeding }\end{array}$ & 99 & 27 & 104 & 32 & 0.79 & $0.57-1.10$ \\
\hline $\begin{array}{c}\text { Complementary } \\
\text { breast-feeding }\end{array}$ & 20 & 5 & 20 & 6 & 0.83 & $0.43-1.58$ \\
\hline $\begin{array}{l}\text { Total } \\
\text { breast-feeding }\end{array}$ & 119 & 32 & 124 & 38 & 0.79 & $0.58-1.08$ \\
\hline
\end{tabular}

$\overline{\text { Total breast-feeding }=\text { exclusive breast }- \text { feeding }+ \text { complementary breast- }}$ feeding.

${ }^{\text {a }}$ From univariate logistic regression analysis.
Table 4

Determinants of breast-feeding at 3 months in multivariate logistic regression analysis

\begin{tabular}{|c|c|c|c|c|c|}
\hline & \multirow[t]{2}{*}{$n=698$} & \multicolumn{2}{|c|}{$\begin{array}{l}\text { Conventional analysis } \\
\text { fixed effects model }\end{array}$} & \multicolumn{2}{|c|}{$\begin{array}{l}\text { Multilevel analysis } \\
\text { random intercepts } \\
\text { model }\end{array}$} \\
\hline & & OR & $95 \% \mathrm{CI}$ & OR & $95 \% \mathrm{CI}$ \\
\hline Control & 330 & 1.00 & Reference & 1.00 & Reference \\
\hline Intervention & 368 & 0.82 & $0.62-1.07$ & 0.82 & $0.58-1.14$ \\
\hline \multicolumn{6}{|l|}{ Maternal age } \\
\hline$<25$ years old & 63 & 1.00 & Reference & 1.00 & Reference \\
\hline $\begin{array}{l}25-30 \text { years } \\
\text { old }\end{array}$ & 311 & 0.99 & $0.56-1.75$ & 0.99 & $0.53-1.85$ \\
\hline$\geq 31$ years old & 324 & 1.13 & $0.60-2.12$ & 1.14 & $0.59-2.16$ \\
\hline \multicolumn{6}{|l|}{$\begin{array}{l}\text { Maternal } \\
\text { education }^{\mathrm{a}}\end{array}$} \\
\hline Low & 138 & 1.00 & Reference & 1.00 & Reference \\
\hline Middle & 390 & $1.98^{* *}$ & $1.27-3.10$ & $1.98^{*}$ & $1.20-3.28$ \\
\hline High & 170 & $4.36^{* * *}$ & $2.75-6.91$ & $4.36^{* * *}$ & $2.50-7.59$ \\
\hline \multicolumn{6}{|l|}{$\begin{array}{l}\text { Previous BF } \\
\text { experience }\end{array}$} \\
\hline No, multiparas & 108 & 1.00 & Reference & 1.00 & Reference \\
\hline Yes, multiparas & 200 & $10.56 * * *$ & $5.60-19.9$ & $10.56^{* * *}$ & $4.83-23.1$ \\
\hline No, primiparas & 390 & $5.74 * * *$ & $2.59-12.7$ & $5.74 * * *$ & $2.65-12.4$ \\
\hline
\end{tabular}

${ }^{\text {a }}$ Low: primary or basic vocational school; middle: secondary vocational or high school; high: higher vocational school or university.

$\mathrm{BF}=$ breast-feeding

$* * P<0.01$

$* * * P<0.001$.

Interaction terms: Intervention group $\times$ intention, $P=0.57$. Intervention group $\times$ maternal age, $P=0.18$. Intervention group $\times$ maternal education, $P=0.22$. Intervention group $\times$ previous $\mathrm{BF}$ experience, $P=0.83$.

95\% CI 0.58-1.19). This indicates that the differences in prepartum intention between control and intervention groups did not confound the main results. The survival curves indicated only a marginal difference in the rate of continuation of $\mathrm{BF}$ between the intervention and control groups (Fig. 2). In the Cox's regression analysis, the

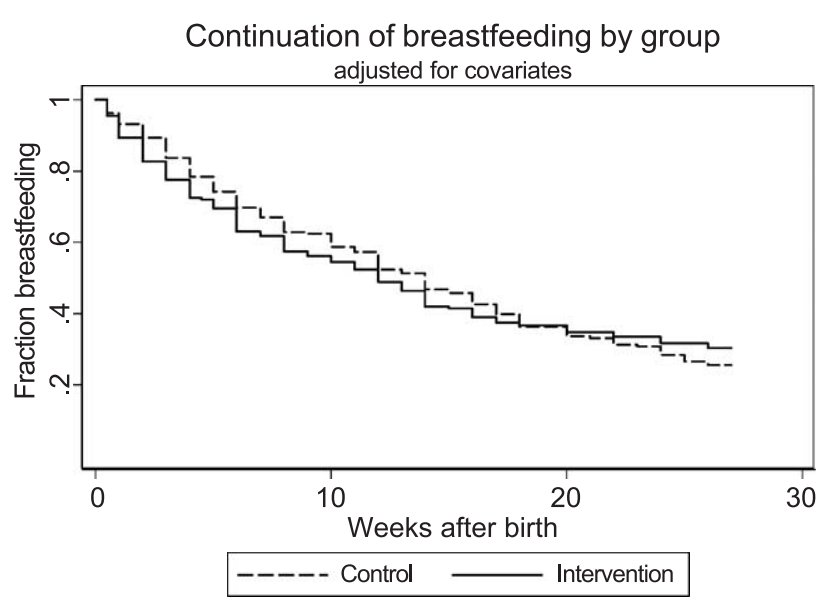

Fig. 2. The survival curve of the continuation of breast-feeding adjusted for covariates (maternal age, maternal education, and previous breast-feeding experience; intervention group $n=245$, control group $n=224$, from Cox's regression analysis). 
hazard ratio for discontinuation of BF was 0.99 (95\% CI 0.93-1.06) when comparing intervention and control groups (controlling for maternal age, maternal education, and previous $\mathrm{BF}$ experience).

At the level of the caregivers, in the year before the intervention (2000), the rate of BF reported in the registry forms in the intervention centers was $25.8 \%$ (123/477) but $31.1 \%(146 / 470)$ in the control centers. In the first year of the intervention period (2001), the rate was $31.0 \%$ (207/ $668)$ in the intervention centers and $27.6 \%(196 / 710)$ in the control centers. In the last half year of the intervention period (2002), the rates were $30.0 \%(76 / 253)$ and $30.1 \%$ (47/156), respectively. When the rates of 2001 and 2002 were taken together, none of the differences was statistically significant (difference in trend between 2000 and $2001+2002, P=0.32$; difference between intervention and control group, $P=0.97$; interaction between trend and group, $P=0.09$; from multilevel logistic regression analysis with random intercepts for the child health centers). In sum, no intervention effect was found.

\section{Process evaluation}

Opinions of mothers about the feeding advices given by the caregivers were not more positive in the intervention group than in the control group, with the exception that they reported slightly less contradictory feeding advice $(P=$ 0.04) (Table 5).

Eighty percent of the caregivers reported that they obtained good or sufficient behavioral skills to carry out the program. Of the 25 caregivers in the intervention centers, $96 \%$ paid attention to the pros of BF, $52 \%$ to the cons, $72 \%$ to the barriers, and $68 \%$ to the social influences of BF during the contacts with the mothers. Eighty-eight percent always (or mostly) experienced support from their colleagues, $80 \%$ from the lactation consultants, and $72 \%$ from the management. However, only $33 \%$ almost (or mostly) experienced support from the midwives. All the caregivers $100 \%$ reported that they knew the materials and generally used them. Only 2 out of 25 caregivers from the intervention centers reported that they had been substituted by caregivers from the control centers (for $10 \%$ and $25 \%$ of their time, respectively) and 3 out of 25 caregivers had substituted for a caregiver in the control centers (for 5\%,5\% and $10 \%$ of their time).

Caregivers in the intervention centers were slightly more positive about the lactation consultants than those in the control centers, but the differences did not reach statistical significance (Table 5).

Table 5

Opinions of mothers about the feeding advices and opinions of caregivers about the care of the lactation consultants

\begin{tabular}{|c|c|c|c|c|c|c|}
\hline & Scale $^{\mathrm{a}}$ & No. & $\begin{array}{l}\text { Intervention cohort, } \\
\text { mean }(\mathrm{SD})^{\mathrm{b}}\end{array}$ & No & $\begin{array}{l}\text { Control cohort, } \\
\text { mean }(\mathrm{SD})^{\mathrm{b}}\end{array}$ & $P$ value $^{\mathrm{b}}$ \\
\hline \multicolumn{7}{|l|}{ Opinions of mothers $(n=617)$ about feeding advice } \\
\hline \multicolumn{7}{|l|}{ Are you satisfied with feeding advice by } \\
\hline Hospital nurse $(n=342)$ & $1-5$ & 187 & $2.53(1.09)$ & 155 & $2.35(1.07)$ & 0.13 \\
\hline General practitioner $(n=242)$ & $1-5$ & 139 & $2.31(0.84)$ & 105 & $2.31(0.89)$ & 0.96 \\
\hline Pediatrician $(n=226)$ & $1-5$ & 127 & $2.35(0.95)$ & 99 & $2.30(0.89)$ & 0.73 \\
\hline Child health care nurse $(n=568)$ & $1-5$ & 300 & $1.98(0.75)$ & 268 & $2.05(0.76)$ & 0.30 \\
\hline Child health care physician $(n=566)$ & $1-5$ & 297 & $2.01(0.79)$ & 269 & $2.10(078)$ & 0.16 \\
\hline Lactation consultant $(n=101)$ & $1-5$ & 73 & $2.07(0.84)$ & 28 & $2.18(1.02)$ & 0.58 \\
\hline \multicolumn{7}{|l|}{ Did the caregivers reckon with your own opinion? } \\
\hline Hospital nurse $(n=484)$ & $1-5$ & 262 & $3.29(1.02)$ & 222 & $3.30(1.04)$ & 0.87 \\
\hline General practitioner $(n=487)$ & $1-5$ & 260 & $3.41(0.85)$ & 227 & $3.39(1.00)$ & 0.78 \\
\hline Pediatrician $(n=462)$ & $1-5$ & 244 & $3.29(0.88)$ & 218 & $3.33(0.93)$ & 0.60 \\
\hline Child health care nurse $(n=591)$ & $1-5$ & 312 & $3.76(0.92)$ & 279 & $3.71(1.05)$ & 0.60 \\
\hline Child health care physician $(n=597)$ & $1-5$ & 317 & $3.76(0.91)$ & 280 & $3.67(1.04)$ & 0.27 \\
\hline Lactation consultant $(n=395)$ & $1-5$ & 211 & $3.40(0.92)$ & 184 & $3.27(0.97)$ & 0.15 \\
\hline Satisfaction with the reach of caregivers? $(n=610)$ & $1-5$ & 327 & $2.05(0.87)$ & 283 & $2.03(0.84)$ & 0.84 \\
\hline Did you receive contradictory feeding advice? $(n=616)$ & $1-5$ & 329 & $1.71(0.45)$ & 287 & $1.79(0.41)$ & 0.04 \\
\hline \multicolumn{7}{|c|}{ Opinions of caregivers $(n=40)$ about the care of lactation consultants } \\
\hline \multicolumn{7}{|c|}{ How desirable is it for you to have the possibility } \\
\hline To refer to them? & $1-5$ & 25 & $3.92(0.28)$ & 15 & $3.73(0.88)$ & 0.34 \\
\hline To consult them? & $1-5$ & 25 & $3.96(0.20)$ & 15 & $3.86(0.35)$ & 0.27 \\
\hline \multicolumn{7}{|l|}{ Satisfaction with } \\
\hline Their reach & $1-5$ & 25 & $2.60(0.76)$ & 15 & $2.40(0.91)$ & 0.48 \\
\hline Their quality of care & $1-5$ & 25 & $2.96(0.79)$ & 15 & $2.80(0.68)$ & 0.50 \\
\hline Their quickness of response to caregivers & $1-5$ & 25 & $2.64(0.76)$ & 15 & $2.60(0.74)$ & 0.87 \\
\hline Their quickness of response to mothers & $1-5$ & 25 & $2.80(0.76)$ & 15 & $2.67(0.62)$ & 0.55 \\
\hline Their report to caregivers & $1-5$ & 25 & $2.76(0.97)$ & 15 & $2.27(0.70)$ & 0.07 \\
\hline
\end{tabular}

${ }^{\text {a }} 1=$ not at all, $5=$ very much.

${ }^{\mathrm{b}}$ From $t$ test. 


\section{Program evaluation}

The introduction training was followed by 19 of the 25 caregivers. The other six persons were absent during this training or started to work after the training and received a group introduction. Twenty-two caregivers followed the refresh trainings.

Ninety-six percent of the mothers in the intervention group received the mother's booklet, which was used in most contacts by $57 \%$, by $58 \%$ of the child health care nurses, and by $53 \%$ of the child health care physicians.

With regard to the program, $56 \%$ of the caregivers found it (fairly) difficult to carry out but $64 \%$ succeeded in carrying it out always (or mostly) at each contact. Ninetysix percent found the program clear and understandable, and $92 \%$ were stimulated by the program to give attention to BF always (or mostly). When we asked whether this program would merit implementation on a national scale, $84 \%$ reported that this would be (very) meaningful and 54\% were willing to carry it out in the future. Forty-four percent reported that the program took more time than usual: $80 \%$ reported that they had longer home visits (12 min more per caregiver), 27\% had more home visits (4 min more per month per caregiver), $72 \%$ had longer consultations (7 min more per caregiver), and $44 \%$ had more consultations (12 consultations more per month per caregiver). During the first 3 months, the mean time they spent on BF counseling during the home visits was $16.6 \min (\mathrm{SD} 9.4, n=16)$ in the intervention group and $16.9 \min (\mathrm{SD} 6.1, n=14)$ in the control group; the mean time spent during the consultations at the child health care centers was $9.1 \mathrm{~min}(\mathrm{SD} 7.4, n=19)$ in the intervention group and $5.8 \min (\mathrm{SD} 1.5, n=18)$ in the control group. The caregivers gave the program a report mark of 7.3 (SD 0.74$)$ on a scale of $1-10(1=$ very low to $10=$ excellent $)$. Sixty-four mothers $(16 \%)$ from the intervention group were referred to the lactation consultants, namely, $19(30 \%)$ by caregivers of the maternity care, 44 $(69 \%)$ by caregivers of the child health care, while one mother $(2 \%)$ contacted the lactation consultant directly. Most common reasons for referral were doubt about drinking of the infant $(21 \%)$, crying infant $(11 \%)$, and pain during feeding (11\%).

\section{Discussion}

There were no significant differences between the intervention and control groups in the rates of BF at birth, or 3 months, or later. Before discussing the implications, we will review the methodological quality of the trial: the comparability of the centers, caregivers, and participants; the contrast between the intervention and control groups and the comparability of cointerventions; the comparability of the outcome measurement; and the statistical power.

With respect to the comparability of the centers, selfselection of the centers was excluded because all the home health care organizations agreed to participate before the start of the trial and all 10 centers continued without dropout. To avoid self-selection of pregnant women to the intervention of their choice, no information was made public whether a center participated in the intervention or control groups; and nonparticipation in the trial occurred before the information was given about the intervention. We had no selective dropout by migration of mothers to another center if they were not pleased with the intervention. At baseline, there was no difference in knowledge between the caregivers. Two years before the start of the intervention (1999), the 3-month BF rates did not differ between the intervention and control regions due to the prestratification and cluster randomization; however, in the year before the intervention (2000), the rate was lower in the intervention centers $(25.8 \%)$ than in the control centers $(31.1 \%)$. We were surprised by this difference but noted that $\mathrm{BF}$ rates varied greatly between the centers as well as over the years. The variability between the centers was taken into account in the multilevel analysis. Participating mothers in the intervention and control groups were reasonably comparable with regard to prognostic variables at baseline, but a difference in the intention to breast-feed was present to the detriment of the intervention group (66\% vs. $71 \%$ in the control group). However, in a stratified analysis, no intervention effect was found in the subgroups of women with and without prepartum intention to carry out BF.

With respect to the contrast between intervention and control groups, the execution of the intervention was according to the planning: all the caregivers followed the training and received two refresh trainings; during the intervention period, there were few new caregivers who also received a short individual training. Caregivers reported that they gave attention to the attitudes, social support, and self-efficacy problems during most of the consultations, had self-confidence in carrying out the program, and felt support from others. The majority of mothers and caregivers used the materials. To avoid an intervention effect resulting from the informed consent procedure and the questionnaires, the informed consent letter was identical for the intervention and the control groups, blinding the aim of increasing BF rates; and the questionnaires had similarly phrased questions about the ASE determinants for formula feeding and BF. The centers were geographically separated. Hence, exchange of information between caregivers of intervention and control centers was avoided. Nevertheless, we cannot exclude that the caregivers had exchanged their knowledge of the training in the health counseling and stimulated each other to promote BF. However, the specific effect of such an exchange could have only been minimal because health counseling is a specific approach, which only can be learned by training. The instruction materials and other supporting measures (the mother's booklet and free access to lactation consultants) were only available in the intervention group. With respect to cointerventions, no new activities that could have diminished the contrast between the intervention and 
control groups were introduced during the intervention period.

With respect to the comparability of outcome measurement, the participants and the caregivers could not be blinded for the intervention; consequently, the outcome measurement could have been influenced by social desirability or by expectations about the intervention effect. However, if this were the case, this would have led to discrepancies between the $\mathrm{BF}$ data from the questionnaires and from the registry forms of the individual mothers. A comparison found only $4 \%$ discrepancies. The follow-up was nearly complete; differential loss to follow-up between the intervention and control groups can therefore be excluded.

The intended size of our trial $(253+253)$ was determined to detect an absolute difference of $10 \%$ between the BF rates at 3 months in the intervention group (31\%) and the control group $(21 \%)$ with $80 \%$ power (alpha 0.05 , one sided). The actual number of participants $(368+330)$ far outnumbered this, and the actual $\mathrm{BF}$ rate in the control group was higher $(38 \%)$ to the effect that a $10 \%$ higher rate in the intervention group (48\%) could have been detected with a power of $83 \%$. In the multilevel analysis, some power is lost due to the variation between clusters. The upper confidence limit of the odds ratio of the main intervention effect (1.14) indicates that it is unlikely that a large intervention effect was missed.

\section{Conclusion}

We have no indications of major biases in the design or execution of the trial. Studies in other fields have shown that the effectiveness of health promotion programs is greatly dependent on the quality of planning [20]. In our study, we addressed the steps identified by most planning models [4] and developed our health counseling model on the determinants resulting from the study [5]. Furthermore, we reviewed intervention trials for $\mathrm{BF}$ promotion programs. Effective programs were programs containing a mix of interventions. In spite of fulfilling these conditions, the present program was not shown to be effective.

Several explanations for the lack of effectiveness can be given. First, the choice of professionals included in the intervention was limited. We could not employ midwives, maternity assistants, or pediatricians in our research study since their practices overlapped the child health care centers to such an extent that it would not be possible to create separate intervention and control centers and had therefore a gap in support in the perinatal period. Mothers received only an intervention during the home visits 2 months before and 14 days after the parturition and the following intervention took place at 1 month. We could not use mass media or regional magazines to support the program since contamination had to be avoided.

A second explanation is that health counseling in this setting has certain limitations. The health counseling model has been successfully applied to smoking prevention; nev- ertheless, there is a difference between BF and smoking. Discontinuation of BF is mostly irreversible, contrary to smoking relapse for which repeated opportunities are possible. In addition, there is a cheap and easy alternative available for BF (formula feeding) and especially easy for working mothers. Possibly health counseling lays too much emphasis on the difficulties of BF, while women like to see $\mathrm{BF}$ as easy and cozy. Such an adverse effect may also have been evoked by attention to early detecting of BF problems.

A third explanation is that the necessary conditions were possibly not present to let the program be successful. A precondition of the program was that the knowledge of caregivers about breast-feeding was sufficient in the region. We assumed that knowledge would be sufficient because the home health care organizations organized annual breastfeeding introduction and booster trainings, before and during the study period (and not different between intervention and control groups). Furthermore, baseline results as measured in the trial revealed that most caregivers scored sufficiently on a breast-feeding knowledge test. A limitation of this test may be, however, the lack of reference data for this test in the Netherlands. Hence, we cannot be completely confident that the condition of sufficient knowledge of breast-feeding was met.

A fourth explanation for the absence of effectiveness might be a diffuse increase of $\mathrm{BF}$ attention in both regions, at the level of the participants by a possible intervention effect of the repeated questionnaires and, at the level of the caregivers by increased attention for $\mathrm{BF}$ in their organizations. On the other hand, much attention was devoted to early detection of $\mathrm{BF}$ problems. We compared the percentages from our study with the annual national percentages [21]. During the last 5 years (1997-2002), there was a rise in percentages of exclusive BF at birth from $70 \%$ to $80 \%$ (and at 3 months from $17 \%$ to $35 \%$ ). Possibly, the increased attention by professionals and mass media may have contributed to this increase. In the Netherlands, the certification of the maternity care in relation to the Baby Friendly Hospital Initiative had a positive effect on the initiation but not on the duration of BF [21]. Planned programs such as our program or the Baby Friendly Hospital Initiative appear not to contribute to this increasing trend in $\mathrm{BF}$ duration.

Lastly, availability of free lactation consultancy was not shown to make a difference in BF continuation in spite of its high uptake in the intervention group. We have found no trials in which lactation consultancy was evaluated as an isolated intervention, but one trial that included it in combination with early discharge showed that it was effective [22].

\section{Recommendations}

To summarize, we found no effect of our BF promotion and support program, and no major flaws in the design or execution of the trial could explain this. We conclude that 
none of the elements in our program is effective (health counseling; early signaling and referral for free lactation consultancy). Programs of BF promotion reviewed by Fairbank et al. [2] or BF support reviewed by Sikorski et al. [3] were shown to be effective in many trials but ineffective in many others, and when comparing them it is hard to tell which mix or intensity of interventions is decisive. Points of improvement in our program are the categories of caregivers involved (maternity assistants, midwives, peer counselors), the number and duration of contacts, especially in the first weeks after parturition, and more emphasis on the continuation steps in health counseling with avoidance of overemphasis on BF problems. Further improvements of breastfeeding support may need a combination of attention to behavioral determinants at the caregivers' level (mesolevel) and environmental and cultural change (macrolevel), such as the conditions for combining work and breast-feeding. The latter may have great impact, as can be seen by the high $\mathrm{BF}$ rates in Scandinavian countries, but goes beyond the kind of programs that can be experimentally tested.

\section{Acknowledgments}

The development and evaluation plan was submitted as a grant proposal for the National Prevention Program of ZONMw ("Netherlands Organization for Health Research and Development"), was approved in 1999, and started in 2000. The authors thank ZONMw and the CZ-group for their financial support. Furthermore, we would like to express our gratitude to the following home health care organizations for their collaboration: The Home Health Care West-Mining Area, The Home Health Care MiddleLimburg, and ZorggroepThuis South-East Limburg. Finally, we would like to thank the members of the steering committee for their advice and support during the research project.

\section{References}

[1] Lanting CI, Herschderfer K, Van Wouwe JP, Reijneveld SA, Peiling melkvoeding van zuigelingen 2001/2002 en het effect van certificering op de borstvoedingscijfers. Leiden: TNO-PG, 2002.309, 2002.

[2] Fairbank L, O'Meara S, Renfrew MJ, Woolridge M, Sowden AJ, Lister-Sharp D. A systematic review to evaluate the effectiveness of interventions to promote the initiation of breastfeeding. Health Technol Assess 2000;4:1-171.

[3] Sikorski J, Renfrew MJ, Pindora S, Wade A. Support for breastfeed- ing mothers (Cochrane review). Oxford: The Cochrane Library, 2003. pp. 1-38 (update Software).

[4] Kools EJ, Thijs C, De Vries H. The ABC of breastfeeding. A planning model for health promotion applied to breastfeeding in the Netherlands. A Window to the Future. 2003. (Submitted for publication).

[5] Termote M, De Vries H, Kools EJ, Thijs C. Psycho-social factors associated with the duration of breastfeeding. A Longitudinal Study. (Submitted for publication).

[6] De Vries H, Mesters I, Van der Steeg H, Honing C, The general public's information needs and perception regarding hereditary cancer: an application of the integrated change model. Patient Educ Couns [in press].

[7] De Vries H, Lezwijn J, Hol M, Van der Steeg M, Skin cancer prevention: behavior and motives of Dutch adolescents. European Journal of Cancer prevention [in press].

[8] De Vries H, Mudde A, Kremers S, Wetzels J, Uiters E, Ariza C, et al. The European smoking prevention frame work approach: short terms effects. Health Educ Res 2003;18:649-63.

[9] Ilca. International Lactation Consultant Association. Available at: http://www.ilca.org.

[10] Kramer MS, Kakuma R. The optimal duration of exclusive breastfeeding. A systematic review. Geneva Switzerland: WHO, 2002 (WHO/NHD/01.08 WHO/FCH/CAH/01.23).

[11] Gerards F, Hospers H. Health counseling: a strategy to accompany patient guidance. Neder Tijdschr Diëtist 1991;46(5):132-7.

[12] Gerards F. Health counseling. In: Damoiseaux V, van der Molen HT, Kok GJ, editors. Health education and behavioral change. Assen: Van Gorcum; 1993. p. 353-63.

[13] Pieterse ME, Seydel ER, De Vries H, Mudde AN, Kok GJ. Effectiveness of a minimal contact smoking cessation program for Dutch general practitioners: a randomized controlled trial. Prev Med 2001; 32:182-90.

[14] Bolman C, De Vries H, Van Breukelen G. A minimal-contact intervention for cardiac inpatients: long-term effects on smoking cessation. Prev Med 2002;35:181-92.

[15] Mc Guire EM. Attitudes and attitude change. New York: Lawrence Erlbaum Associates; 1985.

[16] De Vries H, Kok GJ. From determinants of smoking behavior to the implications for a prevention program. Health Educ Res 1986;1: $85-94$.

[17] De Vries H. Planning and evaluating health promotion. In: Scott D, Weston R, editors. Evaluating health promotion. Cheltenham: Stanley Thornes, 1998. p. $92-108$.

[18] Kools EJ, Thijs C, De Vries H. The behavioral determinants of breastfeeding in the Netherlands: predictors for the initiation of breastfeeding. (Submitted for publication).

[19] StataCorp. Stata statistical software release 7.0. College Station (TX): Stata; 2001.

[20] Green LW, Kreuter MW. Health promotion planning: an educational and ecological approach. Third ed. California: Mayfield Publishing Company; 1999.

[21] Lanting CI, Herschderfer K, Van Wouwe JP, Reijneveld SA, Effect van invoering van het "Baby Friendly Hospital Initiative" op het geven van borstvoeding in Nederland. Leiden: TNO Preventie en Gezondheid; PG/Jeugd 2003.212, 2003.

[22] McKeever P, Stevens B, Miller K-L, MacDonell JW, Gibbins S, Guerriere D, et al. Home versus hospital breastfeeding support for newborns: a randomized controlled trial. Birth 2002;29:258-65. 